\title{
Memória e conhecimento do mundo: coleções de objetos, impressos e manuscritos nas livrarias de Portugal e Espanha, séculos XV-XVII
}

Ana Paula Torres Megiani ${ }^{1}$

RESUMO: $\bigcirc$ artigo trata de uma época em que a idéia da coleção especializada não existia (séculos XVI e XVIII), quando escrita e imagem, forma e conteúdo encontravam-se reunidos em um mesmo conjunto. Nas Câmaras de Maravilhas e Gabinetes de Curiosidades da Alta Idade Moderna, objetos exóticos, animais empalhados, pinturas, gravuras, impressos e manuscritos ocupavam o mesmo espaço como forma de apreensão do conhecimento do mundo. Homens como Manoel Severim de Faria, em Portugal, e Jerônimo de Mascarenhas, na Espanha, ambos contemporâneos da União Ibérica, estão entre esses possuidores de livrarias privadas; representantes de um tipo de letrado nos moldes do Renascimento que desapareceram com o surgimento dos métodos classificatórios e científicos do "colecionismo", difundidos a partir da segunda metade do século XVII.

PALAVRAS-CHAVE: Colecionismo. Oralidade. Cultura escrita. Cartografia. Séculos XVI-XVII.

ABSTRACT: This article describes a period of time when the concept of specialized collecting did not yet exist ( $15^{\text {th }}$-1 $7^{\text {th }}$ century), when text and image, form and content were to be found together in one ensemble. In the Wunderkammer (Chambers of Wonders) and Wunderkabinett (Cabinets of Wonders) of the Late Modern Age, exotic objects, stuffed animals, paintings, prints, printed matter and manuscripts were gathered in the same space, reflecting an attempt to grasp the knowledge of the world. Men like Manoel Severim de Faria in Portugal and Jerônimo de Mascarenhas in Spain, both contemporaries of the Iberian Union, are among those who owned private libraries. Such men represented a kind of Renaissance scholar that disappeared with the advent of classification and scientific methods used in "collecting" and disseminated as of the second half of the $17^{\text {th }}$ century.

KEYWORDS: Collecting. Oral tradition. Written culture. Cartography. 16 $6^{\text {th }} 17^{\text {th }}$ century.

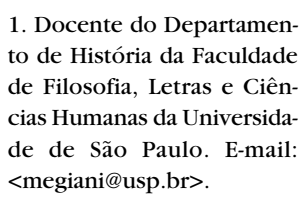

$<$ megiani@usp.br>. 
2. Ver Diogo Ramada Curto (1988, p.110-111).

3. Ver Vespasiano (1963).

4. Cf. Matthew Battles (2003, p.74).

5. Ver J. M. Prieto Bernabé (2005). O autor, que investiga a posse e leitura de livros de história na Madrid do início do século XVII, lida com 1.307 livrarias particulares, de diferentes tamanhos, presentes em $31,7 \%$ de um total de 4.126 inventários.

6. Ver Fernando Bouza (2002, p.109).
Oralidade e visibilidade da memória na Europa moderna.

Durante a Alta Idade Moderna (séculos XV-XVIII), a memória era considerada pelo pensamento ocidental a única forma caracteristicamente humana de conhecimento. As demais ocorriam por intervenção sagrada e manifestavam-se por meio da revelação divina, como as profecias (sonhos), a inspiração e a adivinhação. Diante dessas concepções tão diversas das atuais, a escrita era associada a diversos privilégios de elite, pois representava a invenção humana capaz de contornar o esquecimento e preservar a memória, adquirindo renovada importância e espalhando-se como expressão, em todos os reinos da Europa, das camadas letradas a partir do Renascimento. Assim, toda casa real, e a maior parte das casas nobres, passam a praticar uma verdadeira moda das livrarias, como afirmou Diogo Ramada Curto, que eram formadas por vários tipos de obras reproduzidas, a partir de originais ou traduções raras que circulavam entre cortes, palácios, conventos e universidades².

Compostas - antes da invenção da imprensa - por volumes predominantemente manuscritos, as livrarias de reis e rainhas, clérigos e aristocratas formavam-se com fins nem sempre ligados ao conhecimento em si. No século XV, a valorização da imagem pública de um senhor italiano, por exemplo, poderia ser um desses objetivos, tal como relatou o livreiro Vespasiano, em sua obra sobre a vida dos homens ilustres de sua época ${ }^{3}$. "Mercador de livros radicado em Florença, ele ajudou a reunir as coleções da biblioteca do Vaticano, da biblioteca Laurenziana e da biblioteca de Federigo, Duque de Urbino"4. Encarregado de constituir os acervos de alguns dos mais poderosos senhores da Península ltálica, dentre eles o do grande Cósimo de Médici, em suas memórias Vespasiano afirmou que tais potentados buscavam, antes de tudo, o reconhecimento social de seus iguais ao disponibilizar a consulta aos volumes produzidos em suas livrarias para todos aqueles homens de letras que as necessitassem. Em Madrid, cerca de um século depois, acredita-se que existiam mais de 1.300 coleções particulares de livros 5 .

Ao lado da escrita, também imagens, objetos e a palavra falada foram fundamentais no esforço de manutenção da memória - de pessoas, lugares e épocas - que se acreditava merecer preservação. $\bigcirc$ surgimento das galerias de retratos de homens ilustres - pintados ou esculpidos - na época do Renascimento, juntamente com os ditos e sentenças de cortesãos célebres, formavam verdadeiros repertórios de memórias que combinam imagem, escrita e oralidade de maneira integrada, apresentando conteúdos explícitos ou herméticos, de acordo com a necessidade da formulação. Para o historiador espanhol Fernando Bouza ${ }^{6}$, no decorrer dos séculos XVI e XVII os atos de escrita-leitura travaram, com os sentidos da visão e da oralidade, um verdadeiro combate pela preservação da memória, combate este que levou à separação entre as formas de expressão conhecidas a partir do século XVIII, resultando na predominância da combinação ler-escrever para a preservação do conhecimento. Até o final do século XVII, a escrita era considerada uma imitação do visual e do oral, diferentemente do resultado da 
disputa entre escrita-leitura e imagem, que termina favorável à escrita no ocidente a partir do XVIII. Desse modo, o ato de escrever passa a ser associado à racionalidade, enquanto a representação por imagens torna-se atributo das artes plásticas no nível erudito, e a oralidade limita-se ao ensino e à educação de analfabetos no nível popular.

Essa dicotomia vai mais longe, pois o racionalismo setecentista ainda fixou, na Europa do Norte, uma ligação direta entre o processo da Reforma Protestante e o desenvolvimento da escrita impressa e da leitura individual, enquanto nas regiões dominadas pela Reforma Católica e monarquias tradicionais teria permanecido o vínculo com a percepção visual do divino; o mesmo antagonismo foi usado para explicar o aparecimento do Barroco na zona do Mediterrâneo 7 .

Lina Bolzoni, autora de um estudo importante sobre as formas de preservação da memória nas coleções italianas da época do surgimento da imprensa, partilha da mesma opinião de Bouza, e afirma:

Trata-se de um código cultural muito distante do nosso, um código em que as palavras dos poetas eram traduzidas em imagens visuais, confrontadas à pintura e representadas pela linguagem do corpo, um código fundado sobre uma ciência das imagens que se forma através de numerosas leituras, atravessa e se assemelha a diferentes formas de expressão, apóia-se na memória e culmina nela mesma ${ }^{8}$.

Atualmente, buscamos entender as formas de comunicação e memória que marcaram a cultura da Alta Idade Moderna como expressões associadas muito mais à necessidade de satisfazer a vontade de saber e comunicar-se do que ao conteúdo propriamente dito dos instrumentos de comunicação. Desse modo, tentamos repensar as relações existentes entre imagens, ou o elemento visual da comunicação, e o predomínio do conservadorismo e da ortodoxia em oposição à escrita, que na concepção pós-iluminista estaria vinculada aos impulsos revolucionário e inovador. As coleções que se formaram na Alta ldade Moderna, a partir de livrarias, galerias de retratos, pinturas e esculturas, e até mesmo as câmaras de maravilhas e gabinetes de curiosidades são expressões dessa forma de conhecimento e memória.

Coleções, conhecimento e memória nas cortes ibéricas

Outra das importantes dimensões da memória estabelecida na relação entre o escrito e o visual durante a Alta ldade Moderna está, justamente, na difusão da formação de coleções conhecidas em toda a Europa como câmaras de maravilhas e gabinetes de curiosidades. Nos reinos da Península lbérica, entre os reis, os primórdios dessa prática podem ser localizados ainda no período da Reconquista e talvez até antes. Contudo, não está ao alcance deste artigo tratar dos períodos de formação e consolidação das representações do poder da
7. "Nesse contexto, e em primeiro lugar, o visual passou a considerar-se, na essência, como uma forma de comunicação oposta à escrita, transferindo-se essa mesma oposição, de maniera automática, para os campos cruciais da luta religiosa (Reforma escrita/Contra-Reforma visual) e política (Novo Regime escrito/Antigo Regime visual)." Idem, p. 111.

8. Ver Lina Bolzoni (2005, p. 8). 
9. Ver Miguel Morán Turina e Fernando Checa (1985).

10. Idem, p. 34. Os autores basearam-se na obra Testamentária de Isabel la Católica, editada em Valladolid por Antonio de La Torre em 1968. Segundo esse estudo, os livros da Rainha Isabel de Castela presentes nesta coleção estão divididos nas seguntes categorias: clássicos $\mathrm{e}$ latinos; traduzidos para o castelhano, italiano e francês; espanhóis; temas profanos; livros de cavalaria, religiosos (a maior parte); formação de príncipes; tratados político-morais; livros de leis; histórias e música. Morán e Checa também foram os responsáveis pelo uso do termo coleção museológica em relação aos conjuntos do tesouro da Rainha Isabel, aparentemente anacrônico.
Dinastia Trastâmara e sua relação com a memória através de conjuntos de objetos. Tomo como ponto de partida, assim, as últimas décadas do século XV, período marcado pelo esforço de unificação política do território ibérico, que resulta inicialmente na aliança entre os reinos de Castela e Aragão. Desse modo, acreditamos encontrar certa coerência com base na idéia de se construir uma monarquia única sobre a Península, guardadas todas as dificuldades e vicissitudes que esse processo implicou, até a sua realização, de fato, na União das Coroas entre 1580 e 1640.

Antes do século XV, define-se como tesouro um conjunto de objetos valiosos, guardados pelos monarcas, tais como jóias, peças em ouro e pedras, pertencentes a um palácio principesco, mas que, dependendo da função, podem denotar também caráter religioso, tais como cálices e outros objetos de culto pertencentes a uma sacristia. $\bigcirc$ humanismo, segundo Fernando Checa e Miguel Morán, acrescenta o sentido de coleção a conjuntos de objetos de conteúdo profano cujo caráter é estritamente privado. $\bigcirc$ primeiro indício desse tipo de conjunto surge na Borgonha, quando Jean, o Bom, filho do duque de Berry, que embora também colecionasse jóias, apresenta a valorização dos objetos pelo conteúdo formal e artístico, além do interesse histórico, incluindo os volumes da biblioteca? .

Enquanto os reis e nobres medievais muitas vezes enterravam-se com seus objetos mais caros e valiosos, ocultando-os de súditos e descendentes, os reis católicos Fernando de Aragão e Isabel de Castela inauguraram a prática de doar sua coleção de jóias - coroa, cetro real e cofres - à capela real de Granada, local sede do casamento secreto, que adquire intenso valor simbólico durante o processo da união entre os dois reinos.

A partir desse momento, o tesouro real passa a ter um valor de coleção, com intuito de visibilidade da soberania régia, valor esse dado pelos próprios monarcas ao conjunto de símbolos que configuraria sua memória, isto é, procedem a uma "museificação", avant la lettre, de seus objetos. Entre esses objetos estão incluídas uma livraria de manuscritos, incunábulos e impressos, uma coleção de pinturas e outra de tapeçarias ${ }^{10}$. As tapeçarias, elementos essenciais dos gabinetes, capelas e decoração dos palácios, capazes de transformar os ambientes burocráticos, domésticos e cortesãos em um mundo colorido e pinturesco, foram geralmente inspiradas em representações religiosas com declarada influência da arte flamenga. Quanto à coleção de quadros da rainha lsabel, essa é considerada o item de maior modernidade na corte dos reis espanhóis, pois entre os nobres ainda não se difundira o gosto por coleções de pinturas. Isabel também preferiu pintores flamengos, mas por razões religiosas, e não, estéticas, pois via a obra de arte com interesses piedosos. Como se sabe, a rainha Isabel também mandou vir, da América, animais, objeto e pinturas, interessada em conhecer os tesouros do Novo Mundo. A ela, seguiram-se os seus herdeiros, recebendo animais, plantas e jóias trazidos por Cristóvão Colombo e seus companheiros.

Assim, a prática - ou "moda" - do colecionismo na Península lbérica a partir do século XVI pode estar associada a ambientes interligados: de um lado, as 
cortes régias, formadas pela agregação de tradições diferentes; de outro, as cortes de nobres e fidalgos, em certa medida inspiradas nas cortes régias, mas com autonomia de existência; e, finalmente, as cortes de clérigos seculares e regulares. Pertencentes às monarquias medievais que formaram a Espanha, muitos tesouros estavam depositados, há tempos, no Alcázar de Segóvia. Em 1503, contudo, foi confeccionado o primeiro livro com a relação de todas as coisas que ali se encontravam. Segundo um viajante da época, havia nesse tesouro uma coleção de estátuas dos reis de Espanha, a mais antiga sendo a de Afonso X, O Sábio ( $1252-1284$ ), sentado em seu trono, com o cetro e o globo nas mãos, representando a alegoria do Império reivindicado pelos castelhanos após a Reconquista ${ }^{1}$.

No meio eclesiástico, coube ao cardeal D. Pedro González de Mendoza, amigo de D. Rodrigo de Boria, o futuro papa Alexandre VI, o papel de principal mecenas do Renascimento espanhol, no tempo dos Reis Católicos. Tendo vivido na cidade de Valladollid na primeira metade do século XVI, o cardeal Mendonza foi grande colecionador de livros impressos e manuscritos, e de peças exóticas ${ }^{12}$.

Contudo, o Imperador Carlos $V$ é que foi o responsável pelo empreendimento de uma coleção de obras e peças exóticas sem precedentes na Península e na própria Europa. Descendente de monarcas das principais casas cortesãs européias: Borgonha e Habsburgo, seu tesouro de relíquias, raridades, cartografia, pinturas e tapeçarias fortaleceu e aportou grande significado simbólico ao hábito de colecionar e expor, já disseminado entre cortes de vice-reis ibéricos, elites eclesiásticas, alta nobreza e fidalguia dos reinos de Castela, Aragão, Nápoles e Calábria, como foi o caso da corte da princesa Germana de Fox, a vice-rainha de Valência.

A partir do reinado de Filipe II, as práticas colecionistas tornam-se uma marca efetiva de consolidação da imagem do rei da monarquia hispânica, tanto em seus domínios ibéricos quanto nas regiões por onde estendeu suas conquistas e possessões. As inúmeras coleções de relíquias constituídas pelo rei Prudente, associadas aos arquivos de manuscritos e impressos régios por ele formados, galerias de pinturas, enfim, toda sorte de agrupamentos de objetos, papéis, imagens e figuras, fizeram da segunda metade do século XVI um momento de intensa busca da fixação da memória e do conhecimento por meio da criação de instituições guardiãs desse "patrimônio", ligadas à realeza, ou à família do monarca. Originam-se dessa época os conjuntos de coleção que formaram o futuro Museo del Prado, a Biblioteca del Escorial e o Archivo General de Simancas.

Todavia, vale observar que há uma grande lacuna na sofisticada coleção de escritos guardados durante os reinados de Carlos V e Filipe II: faltam manuscritos árabes. Desde a Baixa Idade Média, vários acontecimentos bélicos levaram à destruição da maioria deles, criteriosamente escritos e copiados desde o surgimento do Islã e sua expansão pelo ocidente. "Quando Carlos V tomou Tunis em 1536, ordenou que todos os livros escritos em árabe fossem queimados" [... a ponto de "quando Filipe II construiu o Escorial não foi possível achar nenhum manuscrito árabe em todo o reino"13.

Contudo, o interesse de Felipe II por plantas e animais exóticos era

\section{Ibidem.}

12. Ver Víctor Manuel Nieto Alcaide, Alfredo J. Morales e Fernando Checa (1993, p 32). O palácio renascentista do Cardeal Mendoza hoje é sede da Reitoria da Universidad de Valladolid, abrigando em seu interior a biblioteca histórica.

13. Ver Matthew Battles (2003, p. 71-72). O mesmo não ocorreu em Portugal, que preservou, talvez inconsequentemente, um considerável volume de manuscritos árabes, atualmente pertencentes ao acervo da Academia das Ciências de Lisboa. 
14. Ver Fernando Bouza (1999, p.157-158).

15. Carta proveniente de Bruxelas, datada de 5 de maio de 1610. Cf. Bernardo García García (2000, n. 29). enorme, fascínio herdado provavelmente da rainha lsabel, sua bisavó, e também relacionado com a conquista da América e a incorporação do Império português na África e no Oriente a partir de 1580. Ao longo do reinado, ele recebeu inúmeras remessas de bichos empalhados e exemplares vivos que eram mantidos nos jardins dos vários palácios por onde o monarca passava ao menos uma vez por ano. Mas foi em Portugal que Filipe II manifestou o interesse de conhecer Abada, o segundo rinoceronte mantido no território lusitano durante o século XVI. Em carta do dia 30 de jutho de 1582, enviada de Lisboa a suas filhas, ele escreve:

Ontem recebi a notícia da chegada, a quarenta léguas daqui, a um porto, de uma nau das que vêm da Índia que por ser velha veio antes das restantes. Julgo que virá em breve para cá. Não sei o que trazem; soube apenas que vem nesta nau um elefante para o vosso irmão, mandado pelo vice-rei que, de Tomar, enviei à Índia [...] Dizei ao vosso irmão isto do elefante ${ }^{14}$.

Em nota explicativa ao episódio, Fernando Bouza afirma que, em 1583, "o vice rei da India, Francisco de Mascarenhas, enviou a D. Diogo de Áustria um elefante que foi levado ao Escorial", e "de Lisboa foram enviados muitos animais exóticos [como gatos e papagaios] ou suas representações plásticas"

Por tudo isso, podemos afirmar que os monarcas Habsburgo espanhóis, a partir de Carlos V, tornam-se um híbrido de mecenas e colecionistas, pois, além de encomendarem obras a grandes pintores, escultores, arquitetos e jardineiros, compravam e trocavam obras, peças, objetos e todo tipo de imagem com outras cortes européias e seus familiares. Outra prática muito comum entre as cortes principescas da Alta Idade Moderna era o presente, ou troca de conjuntos de peças entre elas, tal como ocorreu com as cortes de Madrid e Flandres. Durante o reinado de Filipe III, por exemplo, a irmã do rei, a arquiduquesa Isabel Clara Eugênia, uma das infantas às quais a carta acima se dirigia, estando distante dos familiares por viver em Flandres escreve ao duque de Lerma a seguinte declaração acerca da parede de retratos que possuía: "Yo los tengo ahora a todos puestos en un aposento que hemos remendado [...] y todo el adorno del mio son los retratos, con que paso la vida, ya que no puedo gozar los vivos"15.

Desse modo, seja nas coleções régias, seja na de nobres letrados e clérigos, ou ainda na parede de retratos da arquiduquesa Isabel Clara Eugênia, observamos uma reunião de objetos, memórias e notícias que aproximam o indivíduo portador aos ausentes, juntando - através da escrita e da forma natural ou representada - a memória de grupos de pessoas de um lado do mundo a outro, impedidas de se conhecerem ou se reencontrarem. Foi sem dúvida a ampliação do espaço do mundo conhecido e dominado que desencadeou a necessidade de aumentar o volume das coleções ibéricas.

Segundo K. Pomian, a remessa de relíquias, objetos, gravuras e animais exóticos, produzidos, comprados ou presenteados, podem apresentar inúmeros significados: 
Assim como nas relíquias, nas curiosidades, nas imagens, "intermediários entre o aquém e o além, entre o profano e o sagrado [...] são objetos que representam o distante, o escondido, o ausente [...] intermediários entre o espectador que os mira e o invisível de que provém [... $]^{\prime \prime}$. No momento em que são subtraídos do âmbito dos objetos de uso para serem isolados no espaço à parte do túmulo ou da coleção, esses objetos se tornam semióforos, portadores de significado ${ }^{16}$.

De maneira análoga, lançando mão dos estudos de Natalie Z. Davis, Fernando Bouza afirma que tanto os retratos quanto as cartas autógrafas ofertadas cumprem papel fundamental na sociedade de corte, pois "na cultura del don el regalo se convertió en un gesto casi necesario porque expresaba amistad y servicio" 17 .

Outra prática muito comum, altamente disseminada nas cortes européias ao longo do XVII, iniciada já no século XVI e associada ao colecionismo, foi a de compra de obras de arte, pinturas, esculturas e outros objetos, a partir de conjuntos disponibilizados após a morte de seus proprietários, como meio para liquidação de contas e dívidas do falecido. As chamadas almonedas eram, em princípio, fonte de aquisição de obras belas e muito valorizadas, mas podiam ocultar também um engodo, caso os compradores não fossem experts no assunto. ○ rei Filipe IV fizera de Diego Velázquez seu mais importante cortesão no campo da arte. Não só de pintar as imagens da corte e da realeza viveu o célebre autor de Las meninas, Velázquez era também um exímio arrematador de almonedas, tendo permanecido duas temporadas na Itália como representante da Coroa espanhola para comprar e encomendar obras de arte, fato que alegrava o rei, mas também the trazia sérias preocupações devido à empolgação que estas viagens provocavam em Diego. Como se sabe, o pintor sevilhano fez-se conhecido na corte papal, tendo por isso sido convidado a realizar o importante retrato do papa Inocêncio $X^{18}$.

Um outro exemplo da preocupação com a arrematação de obras por meio de almonedas ocorreu no ano de 1672, quando Luis XIV da França enviou à corte do rei Carlos II de Espanha os pintores Gabriel Blanchard e Josep Cussat, com o objetivo de escolherem 50 quadros da almoneda de Gaspar de Haro y Guzmán, o marquês del Carpio, para levarem à França. Contudo, o Rei-Sol aconselha seus enviados a verificarem rigorosamente a autenticidade e originalidade das pinturas, pois:

Il est quelquefois à craindre que l'on ayt fair faire des copie des ces beaux tableaux, qui sont si bien faites que ç'on a peine de les discerner d'avec les originaux, et qu'après avoir faire voir les vrais originaux, l'on peut quelques substituer en la place de quelques-uns des copies que l'on a peine à démesler dans la quantité 19 .

Para Morán Turina, as coleções reais espanholas, formadas ao longo de mais de um século, não tinham paralelo com o resto das coleções, da nobreza e de clérigos, criadas até o tempo de Filipe IV. Mas tratava-se provavelmente de uma diferença quantitativa, já que o rei tinha mais quadros de Tiziano, Rubens e
16. Cf. Krzysztof Pomian (1978, p. 32), apud Carlo Ginzburg (2001, p. 93).

17. Cf. Fernando Bouza (2003, p. 107). Ver, também, Natalie Z. Davis (2000).

18. Ver Miguel Morán Turina (2006).

19. Apud Fernando Bouza (2003, p. 93). 
Velázquez do que qualquer outro; contudo, alguns marqueses poderiam até rivalizar com o monarca, possuindo obras especialmente raras e valiosas. É o caso da Vênus do Espelho, de Diego Velázquez, obra que pertencera ao marquês de Heliche ${ }^{20}$.

No tocante à importância dada à cartografia nas cortes carolina e filipina, há diversos estudos, pois era grande o interesse em possuir e exibir nas paredes dos aposentos reais as imagens representadas do mundo, tanto em forma de alegorias como em corografias e planisférios. Para ilustrar esse caso, encontramos, no acervo biblioteca do Mosteiro do Escorial, uma carta de recomendação feita por um conselheiro italiano de Filipe II indicando ao rei um geógrafo português, especialista na confecção de mapas e roteiros de navegação. Com data anterior à viagem de Felipe II a Portugal, nesta carta está destacado claramente o argumento da prestação de serviços e alta fidelidade ao monarca, além de um pedido de ajuda para sustentar esse geógrafo lusitano, que se propõe a passar-se para o lado espanhol mediante a acolhida justa do rei. A esse respeito afirma o italiano Giovanni Battista Gesio;

Luys Jorge Geógrafo Português há sido siempre muy affeccionado a V.M $M^{d}$ y deseoso de su real servicio, esta su voluntad la tiene mostrada y puesta en obra en el tiempo que Don Juan de Borja embaxador de V. Magd estubo en la ciudad de Lisboa y yo tambien me hallava con el por las cosas de la mareacion, porque nos descobrio muchos secretos, y por su medio se cobraron muchos papeles, relaciones y mappas y roteros antiguos que hazen mucho al caso sobre este negocio, y para nuestras pretendencias, y demas cada dia nos dava aviso de lo que pretendian hazer los Portugueses en India en prejuicio di V. M ${ }^{d}$ y de la falsificación que se hazia en Lisboa de los rotteros y relaciones nuebas que venian, en conclusión servi muy bien, e paraque hubiesse alguna gratificación desta su buena voluntad y obra y tambien conociendole Don Juan muy habil en la geografia, y en hazer mappas y pintar Provincias, y q podia hazer servicio a V. Mdescribio dello al Presidente Ju. ${ }^{\circ}$ de Ouando, elqual le respondi que lo enviase en esta corte, o lo llevasse consigo en su retorno que procureria que $\mathrm{V}$. $\mathrm{M}^{d}$ si servise del y le hiciese merced. [...] El estando siempre firme en su proposito y voluntad, de passarse a servicio de V.M $M^{d}$ esperava ocasión y comodidad de poder seguir su intento, en pero por allarse muy necessitado y por no tener de quien confiarse, ni aquien arrimarce a deixado de ponerlo en obra hasta agora que yo fue en la ciudad de Lisboa, el qual viendo me y discubrindome su deseo y firme proposito determine de traerle comigo en la buelta. Y con la mas secretaza y mayor yndustria fue necesaria para esto se puso en obra y sin haver acorrido ningun estorbo por el camiño, agora esta aca, truxele a custa e tengo le en mi casa y do le de comer [...] Supplico V. Md mande darle algun entertenimiento y ocuparle en alguna cosa de su servicio, con que se pueda sostentar, pues yo no tengo tanto de poder sostentar esta carga. Y demas es bien que si reciba este hombre portugues y se le haga merced por dar ejemplo a los otros y para que se entienda que los que se passan al servicio de V.M. ${ }^{d} y$ se comparan a su real grandeça y liberalidad quedan beneficiados y amparados. En que se poderia ocupar este hombre y como y porque fuera mejor par servir, poderia V. M. siendo servido del, cometerlo al licenciado Gamboa, como aquel que ha entendido en lo negocio de la demarcacion, y sabe desde el tiempo de D. Juan de Borja los servicios que ha hecho este hombre, para que lo trate con estes señores del consejo de Yndias, o cometerle a Juan 
de Herrera y q Nosso S' augmente V.M' en Vassalos voluntariosos sevicios, en Madrid a X de junio de 1579.

S.R.M. Besa los pies de V. M. su humilissimo siervo Juan Battista Gesio21.

Trata-se do cosmógrafo Luis Jorge Barbuda, contemporâneo de Fernão de Magalhães, de Duarte Gomes de Solis e de outros navegadores célebres. Súdito na corte portuguesa de D. João III, durante a regência de D. Catarina aproximou-se do italiano Giovanni Battista Gesio, "engenheiro" que, desde 1565, estabeleceu residência em Madrid integrando a Junta de Demarcación de Límites entre España y Portugal e ministrando aulas no colégio do Mosteiro do Escorial $^{22}$.

Nesse sentido, vale acrescentar que os mais antigos antecedentes dos estudos "técnicos" na Espanha remontam à Real Academia de Matemáticas de Madrid, criada em 1582 por iniciativa pessoal de Felipe II, após seu regresso de Portugal. Tendo conhecido os cartógrafos lusos durante sua permanência em Lisboa, o rei Prudente reconheceu que estavam mais adiantados que os espanhóis. Nesse centro de formação, eram outorgados títulos de habilitação para o exercício da profissão de cartógrafo, cujo prestigio se baseou no professorado e matérias práticas; ali se formaram cartógrafos, pilotos, arquitetos e engenheiros, de tal maneira que estas duas últimas especialidades passaram a adquirir certa posição de natureza reconhecida. A Real Academia foi extinta em $1634^{23}$.

A circulação de notícias e relatos manuscritos entre o novo e o velho mundo.

Mas, embora o exotismo dos animais e objetos fosse altamente valorizado nessas coleções - assim como a força representativa da imagem retratada ou gravada -, voltemos à escrita e a seus aspectos de vinculação com a memória do mundo novo.

Dentre os campos mais privilegiados da história da cultura da época Moderna, encontramos, nos últimos tempos, os estudos da história do livro e da leitura, que têm entre seus nomes mais destacados os de autores como Daniel Roche, Lucien Febvre, Roger Chartier, Peter Burke, Robert Darnton, Carlo Ginzburg e Natalie Z. Davis ${ }^{24}$. Graças a esses historiadores, compreendemos que a leitura e a escrita integraram um conjunto de práticas determinantes da cultura ocidental em todos os níveis sociais, mesmo entre a massa dos analfabetos; relatos orais tornam-se escritos, e textos impressos são lidos e representados em voz alta para os iletrados. Para Leila Algranti,

A História dos Livros é na verdade uma área limítrofe e marcada pela interdisciplinaridade, na qual encontramos a participação não só de historiadores, mas também de cientistas sociais e estudiosos da literatura. O que há de comum entre esses estudiosos é que todos se
21. Cf. Carta de Juan Bautista Gesio, na Biblioteca El Escorial.

22. "Los datos sobre su biografía [Juan Batista Gesio] son escasos [...] Las teorías de Gesio eran opuestas al sistema filosófico de Ramón Llull. A partir del año 1573 se instala en Portugal y entabla relación con el cosmógrafo Luis Jorge de Barbuda. Este le proporcionó mapas y roteros de Juan Ponce de León, Juan de Solís y Fernando Magallanes que Gesio trasladó al Consejo de Indias y a la Biblioteca de El Escorial. Todo este material fue objeto de estudio por parte de Juan de Ovando y Juan López de Velasco. Gesio fue uno de los principales consejeros a la hora de recomendar al rey la adquisición de documentos como un mapa de Ovando que había realizado Sebastián Cabot. Incluso le pidió que contratara a Barbuda, un cartógrafo que estaba en el exilio." Cf. <http:// www. artehistoria.jcyl.es /histesp/ personajes/2035.htm>

23. Dados extraídos de: <http://www.upm.es/laupm/ historia.html>

24. Para um balanço desses trabalhos e suas contribuições, ver Roger Chartier (1981). 
25. Leila M. Algranti (2004, p.16).

26. Como se sabe, esta idéia foi abordada pela primeira vez, de modo comparativo entre as Américas portuguesa e espanhola, por Sérgio Buarque Holanda (1991, p. 64-65).

27. Ver Luiz Carlos Villalta (1997, p. 333-334).

28. Em Goa, a tipografia foi criada em 1556; em Macau, no ano de 1588; e, no Japão; as primeiras oficinas surgem em 1590. Cf. Charles R. Boxer $(1975,1981)$. E, também, Manuel Cadafaz de Matos (1997).

29. Ver Ana Paula Torres Megiani (2006). interessam por desvendar o longo e complexo processo que se estende desde a produção até a divulgação e consumo de livros; nas palavras de Robert Darnton, dedicam-se ao "ciclo de vida" dos livros, isto é, como surgem e se difundem na sociedade. Cada fase desse processo é importante e apresenta variações, dependendo do tempo e do local em que ocorre. São segmentos de um circuito de comunicação ${ }^{25}$.

Contudo, o desenvolvimento das pesquisas acerca da cultura escrita no Império português tem nos levado, como vimos anteriormente, à necessidade de ultrapassar as relações entre escrita-leitura-memória formuladas por esses autores, já que se trata de um vasto mundo conectado por meio de papéis escritos, raramente fixados na forma impressa, excetuando-se sempre o caso dos jesuítas, detentores de uma tecnologia comunicativa altamente sofisticada, em função da natureza de sua missão universal civilizadora.

Durante muito tempo se acreditou que, além da exploração agrícola e da escravidão, uma das características mais emblemáticas da colonização portuguesa na América fora a ausência de duas instituições fundamentais da cultura européia pós-renascentista: a imprensa e a universidade ${ }^{26}$. À inexistência dessas instituições, estaria ligado, em grande medida, o suposto "atraso" no nascimento e crescimento de grupos sociais letrados, aqui formados e instruídos, gerando na colônia uma sociedade carente de bases fundamentais da cultura letrada e erudita, desprovida de condições para pensar uma nação independentemente do binômio agrarismo-escravidão ${ }^{27}$. Vale lembrar, entretanto, que, embora não tendo sido criada na América, ao menos em outras partes do Império português existiu imprensa desde a primeira metade do século XVI, marcando, como bem mostrou Charles Boxer, a ação, no Oriente, dos evangelizadores da Companhia de Jesus $^{28}$. Evidentemente, em paralelo ao desenvolvimento da imprensa no reino e nas conquistas, vemos aprimorarem-se os mecanismos de censura inquisitorial e controle da circulação e comercialização de livros e impressos dos mais diversos tipos ${ }^{29}$.

Além disso, se por um lado a ausência de tipografias e universidades tornou-se uma espécie de estigma do "atraso", por outro é necessário ressaltar a importância dada ao ensino da língua portuguesa como forma de controle e vinculação nas relações Portugal-Brasil desde o início do século XVI, tal como se pode observar na seguinte afirmação de Luiz Carlos Villalta:

Quanto à língua, a imposição do português foi vista como forma de preservar a Colônia; porém tal ímpeto foi contrabalançado pelas necessidades cotidianas que requereram em linhas gerais e se acomodaram a elas com variações no tempo e no espaço. [...] pelas expectativas dos grupos sociais da Colônia, a língua portuguesa avançou, na proporção da passagem dos séculos, enquanto foram múltiplos os lugares da educação e, inversamente, estreitos os espaços da instrução escolar e dos livros.

Não se pode negar que, atrelada à presença das ordens religiosas detentoras do monopólio do ensino da leitura nos trópicos lusitanos, a ausência de tais instituições de difusão da cultura letrada européia foi determinante para a 
conformação das idéias no Brasil durante o período colonial. Por outro lado, é bastante conhecida a existência de livros impressos clandestinos - como aspecto significativo da formação de núcleos de resistência de colonos letrados contra o acirramento de medidas metropolitanas durante a segunda metade do século XVIII. Contudo, até muito recentemente, pouco se pensou que, ao longo de mais de três séculos de colonização a cultura escrita esteve presente na forma manuscrita - de modo oficial ou não - em todo o edifício comunicativo construído entre Portugal e suas conquistas, bem como nas várias partes do império português. Trata-se de uma constatação simples, de certa maneira óbvia, mas pouco discutida diante do significado que ela possui, pois os estudos mais recentes têm demonstrado que diversas foram as formas de difusão da cultura escrita nos tempos da colonização portuguesa, predominando indiscutivelmente o modo manuscrito.

Nesse sentido, é necessário destacar que os documentos escritos nos séculos XVI, XVII e XVIII, sejam eles impressos ou manuscritos, não podem ser tratados como embriões da escrita pós-ilustrada em sua forma contemporânea. Diferentemente, eles pertencem a um momento específico da cultura ocidental, cujos procedimentos de registro, seleção e organização em volumes e coleções tinham códigos próprios.

Antes de tudo, entendemos que é fundamental levar em conta o caráter hierárquico da sociedade européia que se volta para o novo mundo, na qual um indivíduo apenas letrado não tinha um espaço garantido de atuação junto às diversas esferas de poder e domínio existentes. Eram necessários outros elementos de tradição e negociação para que o portador de conhecimento de letras pudesse ocupar cargos, receber honras, mercês e privilégios régios. Apesar disso, uma monarquia moderna não podia existir sem uma corte de letrados, além de diversos conjuntos de obras impressas e copiadas, assim como as principais casas nobres dos reinos europeus não podiam prescindir do status de possuir livrarias, coleções de gravuras e mapas, sustentando para isso clientelas ligadas ao conhecimento do mundo, à produção artística e ao registro da história.

No que tange a dinâmica de remessa de notícias, relatos e seu papel na consolidação de um conhecimento-memória sobre o mundo novo, A. J. Russell-Wood destacou a importância do registro e da circulação de informações entre as partes do Império português, durante os séculos XV, XVI e XVII, para a construção de um conhecimento novo e de uma memória desse conhecimento, produzido a partir do uso de relatos orais de pessoas que regressaram de temporadas no além-mar, pois "a qualidade, a riqueza e a diversidade das informações reunidas estão patentes em crônicas, narrativas de viagens, relatórios de embaixadores, cartas de jesuítas, diários e correspondência oficial". Ainda segundo Russel Wood,

Parece não ter havido faceta da experiência humana que tenha escapado aos olhos de lince e aos excelentes ouvidos dos portugueses, nas suas peregrinações. [...] Tais informações forneceram os materiais usados por cronistas oficiais e por historiadores, os quais não só tinham acesso, sem restrições, a todos os relatórios que entravam em Portugal, mas podiam

Annals of Museu Paulista. v. 17. n.1. Jan. - June 2009. 
30. Ver A. J. Russell-Wood (1998, p. 97).

31. Ver Ana Paula T. Megiani (2004).

32. São várias as obras atualmente publicadas do autor. Ver, por exemplo, Manuel Severim de Faria (1999, 2003).

33. Ver Ana Paula T. Megiani (2005).

34. A respeito, cf. Maria de Lurdes Correia Fernandes (2000).

35. "Paralelamente, as actividades do Chantre de Évora afiguram-se cruciais na construção de uma rede de homens de letras e na dinamização da vida acadêmica eborense. De facto, a sua biblioteca, consultada por muitos, ocupa o centro de um circuito de comunicação e de relações epistolares à escala planetária. Severim exemplifica bem até que ponto se intensifica, ao longo da primeira metade de Seiscentos, um gosto pelo livro e pela leitura em paralelo com a emergência de uma nova configuração do campo literário." Cf. Diogo Ramada Curto (2002, p. 28). recorrer a testemunho oral riquíssimo daqueles que regressavam de além-mar. Igualmente, conselheiros reais, estrategas militares, prospectores comerciais e até membros do clero recorreram a essas mesmas fontes para tomar decisões no interesse da Coroa, do País e da Cristandade ${ }^{30}$.

Um caso extremamente elucidativo dessa situação é o da livraria de Manuel Severim de Faria (1583-1655), chantre da Sé de Évora, onde foram reunidos cerca de 400 volumes de manuscritos e impressos de vários tipos, tais como folhetos, relações de sucessos, livros e gravuras, sendo uma das poucas coleções privadas existentes no reino de Portugal no período ${ }^{31}$. Trata-se de um conjunto formado por uma malha de correspondências oriundas de várias partes dos reinos de Portugal e Espanha, da Europa, Índia, África e América - desde a última década do século XVI até meados do XVII -, centralizada na cidade de Évora. Inaugurada pelo chantre e continuada por seu sobrinho Balthazar de Faria Severim, a rede de informações resultou na criação de um considerável volume de documentos manuscritos, hoje dispersos e em parte desaparecidos, que se destinavam à composição de obras de história, raramente concluídas, elaboradas predominantemente nas formas de anais e décadas, e remetidas aos correspondentes ${ }^{32}$.

$\bigcirc$ caráter excepcional dos códices de Severim de Faria é determinado pelo fato de vários autores do século XVII terem colaborado nas relações de notícias; em contrapartida, receberam contribuições da livraria de Évora para a composição de suas obras. Além de Luís Mendes de Vasconcelos, Diogo do Couto e Frei Vicente do Salvador ${ }^{33}$, os pesquisadores mencionam conexões com Jorge Cardoso, autor do Agiológio Lusitano, e com João Franco Barreto, que escreveu uma importantíssima relação de obras, a Biblioteca Luzitana, compilação de livrarias existentes em Portugal na primeira metade do seiscentos ${ }^{34}$. Duarte Nunes de Leão também está entre os referidos que partilharam desse ambiente letrado, embora não haja comprovação de que, de fato, Severim de Faria tenha trocado correspondência com ele. Frei Cristóvão de Lisboa, irmão mais novo de Severim de Faria, que vivera entre os nativos do Maranhão na segunda década do XVII, e Ambrósio Fernandes Brandão são os outros correspondentes na América Portuguesa, embora, no tocante ao segundo, seja apenas constatada na livraria do chantre a existência do manuscrito de Diálogos das Grandezas do Brasil, que também permaneceria manuscrito até o século XIX ${ }^{35}$.

Na Espanha, entre as milhares de livrarias privadas acima referidas, encontramos uma coleção especial e similar à de Severim de Faria, formada também por um português que se transferiu para Madrid logo após a anexação de Portugal à Coroa espanhola. Trata-se da importantíssima Coleção Mascarenhas, preservada integralmente na Biblioteca Nacional de Madrid, um dos acervos mais importantes para os estudos do século XVII e consultada por historiadores renomados da época moderna, tanto espanhóis como estrangeiros, como J. A. Maravall, John Elliot, John Lynch, Stuart Schwartz, entre outros. Esta coleção, contudo, tem sido pouco estudada como corpus integral.

Formada pelo português Jerónimo de Mascarenhas, consiste em um 
conjunto de códices - composto por impressos dos mais variados tipos, manuscritos autógrafos e cartas de notícias - muito semelhante ao de Manuel Severim de Faria. $\bigcirc$ acesso aos códices do bispo Mascarenhas nos permite imaginar como seria, então, a livraria do chantre, atualmente desaparecida por ter sido desmembrada desde o início do século XVIII. Nascido em Lisboa, em 1611, e falecido em Segovia, em 1672, Jerónimo era o sexto filho de D. Jorge de Mascarenhas, marquês de Montalvão e primeiro vice-rei do Brasil. Formado e doutorado em cânones em Coimbra, teve uma carreira eclesiástica condizente com o status social de sua família, optando por permanecer ao lado da Coroa espanhola após a Restauração. Sua adesão a Filipe IV, como clérigo da Casa Real e cortesão, rendeu-lhe, já em 1641, um título da Ordem de Calatrava, além da escalada, junto ao monarca, de postos como summilier de cortina e membro do Conselho de Portugal. Em 1647, tornou-se capelão-mór e limosnero-mór da casa da rainha D. Mariana de Áustria e, em 1667, foi nomeado Bispo de Segóvia, local onde faleceu e está sepultado36.

Embora nunca tenha se aventurado a ocupar posições nas inúmeras possessões espanholas fora do território da península, tampouco na América, Jerônimo Mascarenhas foi um incansável colecionador de relações de sucessos, notícias e toda sorte de avisos, movido pelo desejo de se consagrar como um historiador da monarquia, cuja importância revela em um de seus escritos de 1621, que trata de como se deve escrever anais de história: "de que necessita un Reyno mas si de un escriptor verdadero, ó Rey bueno: y siguem no pocos que mas importa a la Republica aquel que este, instó que el buen Rey solo es bueno en su tiempo: y la Historia sy es qual debe, haze a muchos que lo sean con los documentos que presenta de los sucesos passados"37.

Os cerca de cinquenta códices que formam a Coleção Mascarenhas ${ }^{38}$, estão ainda repletos de cartas - originais e cópias - enviadas de todas as cortes mais importantes da Europa, Oriente e Ocidente, além de compilações de documentos antigos, especialmente relativos às relações entre as monarquias de Espanha e Portugal ${ }^{39}$.

Seus textos autorais foram compostos em língua castelhana, opção feita pela totalidade dos autores que se transferiram de Portugal para a corte espanhola no período. Alguns de seus escritos chegaram a ser impressos, mas grande parte permanece até hoje manuscrita. Organizados segundo critério cronológico de interesse do autor, isto é, quando reunia os sucessos de um determinado ano e necessitava de um documento copiado mais antigo, este era anexado ao volume do ano da elaboração. Os volumes apresentam sumários de conteúdos imprecisos, pois não correspondem exatamente aos documentos existentes em cada volume. Na primeira parte dos códices, encontramos os anais do próprio Mascarenhas, ou seja, a síntese de acontecimentos das relações recebidas; em seguida, os textos enviados, provavelmente por copistas que o auxiliavam em arquivos e cortes de Itália e Portugal; na última parte de cada códice, estão os anexos impressos e manuscritos, ou seja, o material bruto do trabalho.

A descrição da organização das fontes nos códices não visa apenas a
36. Sobre Jerônimo Mascarenhas, não existe um estudo especifico, a bibliografia resume-se a artigos muito pontuais, como os de Bonaventura Bassegoda I Hugas (1996), Jesús Antonio Cid (1999) e o de Fernando Bouza (2000). Entre as obras de Mascarenhas publicadas está Viage de la sereníssima reyna Doña Maria Ana de Áustria. Segunda muger de Don Phelipe Quarto deste nombre. Rey Catholico de Hespana hasta la Real Corte de Madrid, desde la Imperial de Viena. Al Rey nuestro señor por Don Hieronymo Mascarenas, Cavallero de la Orden de Calatrava del Consejo de su Majestad en el Supremo de lãs Ordenes Militares de Castilla. Su Sumiller de Cortina. Prior de Guimaraens y Obispo electo de Leirya. Con Privilegio en Madrid por Diogo Diaz de la Carrera ano 1650 .

37. Cf. Jerónimo Mascarenhas, Cualidades de los que ban de escribir bistoria o anales.

38. A numeração dos códices na Biblioteca Nacional de España, em Madrid, abrange os números 2343 a 2393.

39. Agradeço ao Felix Labrador Arroyo a indicação de trabalhos de pesquisadores espanhóis sobre Jerónimo Mascarenhas. 
40. A esse respeito, a pesquisa na Biblioteca Nacional de España nos levou, por indicação de F. Bouza, à localização de uma fonte inédita Relaciones Manuscritas de Portugal desde anno de 1643 ate 1646 - relacionada com o chantre de Évora. Trata-se de um códice manuscrito completo formado por notícias enviadas por autor desconhecido a Manuel Severim de Faria

41. Para a escrita portuguesa da guerra durante a época moderna, em âmbito régio e cortesão, refiro-me aqui ao importante trabalho de Rui Bebiano (2000, cap. 3.).

42. Cf. María Cruz García de Enterría et al. (1996).

43. Um importante estudo sobre a circulação de notícias da América na Europa nos inícios da época moderna é o de Renate Pieper (2005).

44. Com relação às Gazetas, impressas e manuscritas, a bibliografia é vasta. Ver João Luís Lisboa, Tiago C. P. dos Reis Miranda e Fernanda Olival (2002, 2005). mostrar seu caráter material, mas, para além dele, observarmos que cada volume de Mascarenhas permite ao historiador conhecer as camadas de seu processo de escrita e registro da memória. $\bigcirc$ rigor metodológico de Mascarenhas indica uma visão classificatória, o que diferencia esta coleção de notícias da mencionada de Severim de Faria, menos criterioso na organização de seus papéis, mas por outro lado mais sistemático na narrativa cronológica dos seus Anais da História de Portuga $/ 40$.

Dentro desse conjunto, constatamos - sobretudo, ao longo da década de vinte do século XVII - a existência de um volume significativo de pedidos de envio de notícias sobre as ameaças, invasões e expulsão de holandeses nas conquistas portuguesas, que fazem circular entre vários ambientes as relações de sucessos.

A circulação de relatos de batalhas, guerras e sucessos militares intensificou-se por toda Europa na primeira metade do século XVII, em parte devido ao crescimento das atividades relacionadas à escrita e à imprensa nos ambientes ligados à monarquia, igreja e, sobretudo às cortes ibéricas ${ }^{41}$. A escrita, leitura, memória e coleção desses relatos passou a ocupar um lugar de destaque na vida de letrados de diversas categorias sociais, podendo ser conhecidas como um subgênero dentro do próprio gênero "relações de sucessos", que, por sua vez, compreende uma vasta gama de assuntos, tais como, cerimônias da corte e da realeza (entradas, casamentos, batizados, cerimônias fúnebres, e outros), autos-de-fé, fenômenos da natureza (passagem de cometas, eclipses, inundações), milagres, visões ou relatos de sonhos proféticos ${ }^{42}$.

Além disso, lembramos que a difundida prática da elaboração de textos de aconselhamento para resolução de problemas da vida "econômica" do reino, da Coroa e das conquistas, conhecida como arbitrismo, que, embora tenha características textuais e significados específicos, também passa a integrar esses conjuntos de relações, constando invariavelmente nesses códices chamados de miscelâneas. Estamos, portanto, diante de um processo de intensificação e difusão dos modos particulares de coletar, organizar e preservar a informação escrita, associados aos processos de formação da burocracia das monarquias modernas, marcados pela sofisticação das formas de conhecimento e novas configurações sociais nos ambientes de corte, que colocam aos letrados possibilidades de mobilidade através do fortalecimento de vínculos permeados pela escrita ${ }^{43}$. Esses processos integrados proporcionam o surgimento de práticas coletivas e individuais que deram origem a novos mecanismos de seleção e organização da memória, como foi o do nascimento das gazetas de notícias ${ }^{44}$.

Finalmente, entendemos que, assim como as obras de arte e arquitetura constituem o patrimônio e a memória de culturas da edificação de natureza predominantemente estável e imóvel, as narrativas e notícias escritas que, durante os séculos XVI, XVII e XVIII percorreram os mares em meio a peças escravas, ouro e especiarias, formam o edifício de papéis que não foi erigido a partir de corolários tratadísticos e padrões estéticos. Desse modo, a ampla dimensão da escrita descritiva do Império português se constitui como primeiro estágio de uma nova memória, elaborada de maneira extremamente coloquial, muito próxima à oralidade da língua falada, contendo grande riqueza de detalhes com relação 
ao estado das coisas no Brasil, África, Oriente e Portugal, uma espécie de "memória em movimento".

Assim, o estudo de coleções de livros; da circulação de idéias, notícias, relatos e memórias; dos usos da escrita no campo administrativo, nos campos místico-religioso e evangelizador abre enormes vertentes a uma compreensão original dos mecanismos de encontro da cultura européia com as culturas que passaram a se conectar a ela após a criação dos impérios ultramarinos. Isto é, o aprofundamento da análise, no Império português, do sistema de comunicação escrita permite refletir sobre a permanência e a continuidade de práticas culturais desenvolvidas na metrópole que, de certa forma, além de se estenderem aos domínios ultramarinos portugueses, articularam e uniram as diversas partes do império, construindo as bases sobre as quais se efetivou a colonização.

Através da integração dos elementos orais-textuais-visuais, um conjunto de códigos de comunicações expressa e transmite valores simbólicos e significados de vários tipos: econômicos, sociais, políticos, religiosos, étnicos etc. $\bigcirc$ estudo dos sistemas de memória e comunicação é, portanto, um extraordinário veículo de compreensão de autorrepresentações, de identidades e de trocas culturais.

\section{REFERÊNCIAS}

ALGRANTI, Leila M. Livros de devoção, atos de censura. Ensaio de história do livro e da leitura na América portuguesa (1750-1821). São Paulo: Hucitec; Fapesp, 2004.

BASSEGODA I HUGAS, Bonaventura. Jerónimo de Mascarenhas retratado por Pedro de Villafranca. In. Locus Amoenus, Barcelona, n. 2, p. 175-180, 1996.

BATTLES, Matthew. A conturbada história das bibliotecas. Trad. João Vergílio Gallerani Cuter. São Paulo: Planeta, 2003.

BEBIANO, Rui. A Pena de Marte. Escrita da guerra em Portugal e na Europa, séculos XVI-XVIII. Coimbra: Minerva, 2000.

BOLZONI, Lina. La chambre de la mémoire. Modéles litteraires et iconografiques a l'âge de l'imprimerie. Trad. Marie-France Merger. Genève: Droz, 2005.

BOUZA, Fernando (Org.). Cartas para duas infantas meninas. Portugal na correspondência de D. Filipe I para suas filhas (1581-1583). Lisboa: D. Quixote, 1999.

BOUZA, Fernando. Entre dois reinos, uma pátria rebelde. Fidalgos portugueses na monarquia hispânica depois de 1640. In: Portugal no tempo dos Filipes. Política, Cultura, Representações (1580-1668). Trad. Ângela Barreto Xavier e Pedro Cardim Lisboa: Cosmos, 2000. p.271-291.

BOUZA, Fernando. Comunicação, conhecimento e memória na Espanha dos séculos XVI e XVII. Cultura, Revista de História e Teoria das Ideias, Lisboa, v. 19, segunda série, p. 105- 171, 2002 (Centro de História da Cultura, CHAM).

BOUZA, Fernando. Palabra e imagen en la Corte. Cultura oral y visual de la nobleza em el Siglo de Oro. Madrid: Abada, 2003. 
BOXER, Charles R. A tentative check-list of Indo-Portuguese inprints In: FUNDAÇÃO CALOUSTE GULBENKIAN. Arquivos do Centro Cultural Português: Homenagem a Marcel Bataillon, 9. Paris: FCG, 1975. p. 567-599.

BOXER, Charles R. O Império Colonial Português, 1415-1825. Trad. Sebastião Brás. Lisboa: Edições 70, 1981.

CARTA de Juan Bautista Gesio a Felipe II recomendandole a Luis Jorge... Códice. San Lorenzo de El Escorial, Biblioteca El Escorial, L.I.12.

CHARTIER, Roger. L'Ancien regime typographique: reflexions sur quelques travaux recénts (nota critica). Annales, École des hautes études en sciences sociales, Paris v. 36, n. 2 p. 191-209, 1981.

CID, Jesús Antonio. Historia, razón de estado y burocracia: Antonio de Solís contra Jerónimo Mascareñas (1662-1663). Nueva Revista de Filología Hispánica, La Rioja, v. 47, n. 1, p. 73-97, 1999.

CURTO, Diogo Ramada. O discurso político em Portugal (1600-1650). Lisboa: Universidade Aberta, 1988.

CURTO, Diogo Ramada. A história do livro em Portugal: uma agenda em aberto. Leituras, Revista da Biblioteca Nacional, Lisboa, n. 9-10, pp. 13-61, outono-primavera, 2001-2002.

DAVIS, Natalie Z. The Gift in Sixteenth-Century France. Madison: University of Wisconsin Press, 2000.

FARIA, Manuel Severim de. Discursos vários políticos [1674]. Lisboa: Imprensa Nacional; Casa da Moeda, 1999.

FARIA, Manuel Severim de. Notícias de Portugal [1655]. Intr. Francisco A. Lourenço. Lisboa: Colibri, 2003.

FERNANDES, Maria de Lurdes Correia, A biblioteca de Jorge Cardoso (†1669), autor do Agiológio Lusitano: cultura, erudição e sentimento religioso no Portugal moderno. Porto: Faculdade de Letras da Universidade do Porto, 2000.

GARCÍA DE ENTERRÍA, María Cruz et al. (Org.). Las Relaciones de Sucessos en España (1500-1750). Actas del Primer Coloquio Internacional (Alcalá de Henares, 8-9 y 10 de junio de 1995). Paris: Publicaciones de la Sorbonne; Alcalá de Henares: Universidad de Alcalá de Henares, 1996.

GARCÍA GARCÍA, Bernardo. Los regalos de Isabel Clara Eugenia y la Corte española. Intimidad, gusto y devoción. Reales Sítios, v. 37, n. 143, p. 17-27, 2000.

GINZBURG, Carlo. Representação: a palavra, a idéia, a coisa. In: . Olbos de Madeira. Nove reflexões sobre a distância. Trad. Eduardo Brandão. São Paulo: Cia das Letras, 2001.

HOLANDA, Sérgio Buarque. O semeador e o ladrilhador. In: Raízes do Brasil. 23. ed. Rio de Janeiro: José Olympio, 1991.

LISBOA, João Luís; MIRANDA, Tiago C. P. dos Reis; OLIVAL, Fernanda (Orgs.). Gazetas Manuscritas da Biblioteca Pública de Évora, 1 (1729-1731). Lisboa: Colibri, 2002.

LISBOA, João Luís; MIRANDA, Tiago C. P. dos Reis; OLIVAL, Fernanda (Orgs.). Gazetas Manuscritas da Biblioteca Pública de Évora, 2 (1732-1734). Lisboa: Colibri, 2005.

MASCARENHAS, Jerónimo. Cualidades de los que han de escribir bistoria o anales. Relaciones del Año 1621. Madrid, Biblioteca Nacional de España, ms. 2352, fol. 1v. 
MASCARENHAS, Jerónimo. Relaciones Manuscritas de Portugal desde anno de 1643 ate 1646. Madrid, Biblioteca Nacional de España, ms. 8187 (microfilme 13874), 96 fol.

MATOS, Manuel Cadafaz de. A tipografia quinbentista de expressão cultural portuguesa no Ocidente (India, China e Japão). 1997. Tese (Doutorado em História) - Faculdade de Ciências Sociais e Humanas, Universidade Nova de Lisboa, Lisboa, 1997.

MEgIANI, Ana Paula T. O Rei Ausente. Festa e Cultura Política nas Visitas dos Filipes a Portugal (1581 e 1619). São Paulo: Alameda, 2004.

MEGIANI, Ana Paula T. Política e Letras no tempo dos Filipes: o Império Português e as conexões de Manuel Severim de Faria e Luis Mendes de Vasconcelos. In: BICALHO, Maria Fernanda B.; FERLINI, Vera Lucia A. Modos de Governar. Idéias e Práticas Políticas no Império Português. Séculos XVI a XIX. São Paulo: Alameda, 2005. p. 239-256.

MEGIANI, Ana Paula Torres. Imprimir, regular, negociar: elementos para o estudo da relação entre Coroa, Santo Ofício e impressores no mundo português (1500-1640). Anais de História do Além-Mar, Lisboa, n. 7, p. 231-250, 2006.

MORÁN TURINA, Miguel. Estudios sobre Velázquez. Madrid: Akal, 2006.

MORÁN TURINA, Miguel; CHECA, Fernando. El Coleccionismo en España. De la câmara de maravillas a la galeria de pinturas. Madrid: Cátedra, 1985.

NIETO ALCAIDE, Víctor Manuel; MORALES, Alfredo J.; CHECA, Fernando. Arquitectura del Renacimiento en España, 1488-1599. 2. ed. Madrid: Cátedra, 1993.

PIEPER, Renate. Cartas de nuevas y avisos manuscitos en la época de la imprenta. Su difusión de noticias sobre América durante el siglo XVI. In. BOUZA, Fernando (Org.), Cuadernos de Historia Moderna: Cultura epistolar en la alta Edad Moderna. Usos de la carta y de la correspondencia entre el manuscrito y el impreso, an. 4. Madrid: Universidad Complutense, 2005. p. 83-94.

POMIAN, Krzysztof. Collectioneurs, amateurs et curieux. Paris: Gallimard, 1978.

PRIETO BERNABÉ, J. M. “Recibida y admitida de todos...” La lectura de la historia en la sociedad madrileña del Siglo de Oro. Hispania, Revista Española de Historia, Madri, v. 65, n. 221, p. 877-938, sept.-dic. 2005.

RUSSELL-WOOD, Anthony John R. Um mundo em movimento. Os portugueses na África, Ásia e América (1415-1808). Trad. Vanda Anastácio. Lisboa: Difel, 1998.

VESPASIANO. Memoirs: Lives of Illustrious Men of the XV th Century. New York: Harper \& Row, 1963.

VILLALTA, Luiz Carlos. O que se fala e o que se lê: língua, instrução e leitura. In: SOUZA, Laura de Mello e (Org.). História da Vida Privada no Brasil, 1. São Paulo: Companhia das Letras, 1997.

SITES

<http://www.artehistoria.jcyl.es/histesp/personajes/2035.htm>. Acesso em: 30 de maio de 2009.

<http://www.upm.es/laupm/historia.html> Acesso em: 30 de maio de 2009.

Artigo apresentado em 8/2008. Aprovado em 12/2008.

Annals of Museu Paulista. v. 17. n.1. Jan. - June 2009. 